\title{
Frequency, severity and related factors of androgenetic alopecia in dermatology outpatient clinic: hospital-based cross-sectional study in Turkey*
}

\author{
Kubra Esen Salman ${ }^{1}$ \\ Nihal Asli Kucukunal ${ }^{1}$
}

\author{
Ilknur Kivanc Altunay ${ }^{1}$ \\ Asli Aksu Cerman ${ }^{1}$
}

DOI: http:/ / dx.doi.org/10.1590/abd1806-4841.20175241

\begin{abstract}
BACKGROUND: Androgenetic alopecia (AGA) is a patterned hair loss occurring due to systemic androgen and genetic factors. It is the most common cause of hair loss in both genders. In recent years, many studies investigating the relation between systemic diseases and androgenetic alopecia presented controversial results.

OBJECTIVES: In this study we aimed to investigate the frequency of androgenetic alopecia, the presence of accompanying systemic diseases, the relation between body mass index and androgenetic alopecia severity and the association of hyperandrogenemia signs with androgenetic alopecia in patients who referred to our outpatient clinic.

Methods: Patients who referred to our clinic between October 2013 and May 2014 were included in the study. Diagnosis of androgenetic alopecia was made upon clinical findings. Presence of seborrhea and acne in both genders, and hirsutism in women, were examined. Age, gender, smoking habit and alcohol consumption, age of onset of androgenetic alopecia, family history, accompanying systemic diseases and abnormalities of menstrual cycle were recorded.

RESUlTs: 954 patients (535 women, 419 men) were included in the study. Androgenetic alopecia prevalence found was $67.1 \%$ in men and $23.9 \%$ in women. Androgenetic alopecia prevalence and severity were correlated with age in both genders ( $p=0,0001)$. Frequency of accompanying systemic diseases were not significantly different between patients with and without androgenetic alopecia $(p=0,087)$, except for hypertension, which was significantly more frequent in men with androgenetic alopecia aged between 50 and 59 years. Study limitations: Despite the exclusion of other causes of alopecia, differentiation of Ludwig grade 1 AGA from telogen effluvium based on clinical features alone is difficult.

CONCLUSIONS: In our study the rate of androgenetic alopecia was found to be higher than the other studies made in Asian and Caucasian populations.
\end{abstract}

Keywords: Alopecia; Androgens; Epidemiology

\section{INTRODUCTION}

Androgenetic alopecia (AGA) is characterized by follicular miniaturization in a patterned hair loss occurring due to systemic androgen and genetic factors. ${ }^{1,2,3,4}$ The age of onset is usually the $3 \mathrm{rd}$ and 4th decades, but the hair loss starts immediately after puberty and continues progressively. ${ }^{1,5}$ AGA is the most common cause of hair loss in both genders. ${ }^{1,6}$ It may affect a variety of psychological and social experiences, and the individual's quality of life. ${ }^{7,89}$ Different results have been reported about prevalence of AGA depending on ethnic groups. ${ }^{1,5,10,11,12}$ Prevalence of AGA was reported to be $50 \%$ in Caucasian men and $19 \%$ in Caucasian women. ${ }^{13,14}$ Both prevalence and severity of AGA were reported to be lower in Asian and black men than in Caucasians. ${ }^{1,3,10,11}$ According to Hamilton's study, by the age of 30 years the mean prevalence is $30 \%$, and this rate rises to $50 \%$ by the age of 50 years. ${ }^{12,13}$ Phenotype of AGA is different in men and women. In the male pattern, the hairline regresses at the bitemporal regions and balding of the vertex occurs. In the female pattern, there is a diffuse thinning while the frontal hairline is preserved. ${ }^{15,16}$ Despite the different clinical presentations, pathogenesis is the same in both genders.

Considering the presence of patients resistant to anti-androgen therapy, other etiologic factors, apart from androgens, are thought to take part in the pathogenesis. ${ }^{2}$

Over the past 20 years, studies have reported association between AGA and cardiovascular diseases (CVD), metabolic syn-

Received on 10.10.2015.

Approved by the Advisory Board and accepted for publication on 03.06.2016.

* Study conducted at Sisli Hamidiye Etfal Training and Research Hospital, Department of Dermatology - Istanbul, Turkey. Financial support: None.

Conflict of interest: None.

1 Department of Dermatology - Sisli Hamidiye Etfal Training and Research Hospital - Istanbul, Turkey.

(C2017 by Anais Brasileiros de Dermatologia 
drome (MetS), insulin resistance (IR), and hypertension (HT). ${ }^{2}$ Particularly, there is a strong relation between early onset of AGA and early onset of severe coronary artery disease or metabolic syndrome. ${ }^{2,17,18,19}$ The association between AGA and obesity has not been fully understood yet. ${ }^{2,20,21}$

In this study our primary aim was to determine the prevalance and severity of AGA. Our secondary objective were to identify the association between AGA and etiological factors (family history, accompanying systemic diseases, body mass index [BMI], menstrual cycle and hyperandrogenemia) in our outpatient clinic.

\section{METHODS}

A hospital-based, cross-sectional and controlled study was planned. Approval from our hospital's ethics committee was obtained prior to subject enrollment. We consecutively enrolled 954 patients, aged >16 years, between October 2013 and May 2014, in our outpatient clinic. Pregnant women, thyroid or cancer patients were excluded from the study.

Patients' age, gender, weight, height, alcohol consumption and smoking habits, systemic diseases (DM, CVD, HL, HT), family history of AGA, and menstrual cycle in women were recorded. Patients were divided into six subgroups according to age (17-29, 30-39, $40-49,50-59,60-69$, >70 years) while comparing systemic diseases between patients with and without AGA. Concomitant hyperandrogenemia symptoms (acne vulgaris, seborrhea and hirsutism) were investigated and the diagnosis of SAHA syndrome was made if the patient had seborrhea, acne, hirsutism and androgenetic alopecia.

Presence of obesity was assessed with BMI (Height/Weight ${ }^{2}$ $\left.\left[\mathrm{kg} / \mathrm{m}^{2}\right]\right)$. Patients were classified based on BMI as follows: $<25 \mathrm{~kg} /$ $\mathrm{m}^{2}=$ normal; $25-30 \mathrm{~kg} / \mathrm{m}^{2}$ = overweight; $\geq 30 \mathrm{~kg} / \mathrm{m}^{2}=$ obese. $^{22}$

Diagnosis of AGA was made with clinical examination of the patients. Patients with chronic telogen effluvium, diffuse alopecia areata, as well as patients using drugs that may cause alopecia were excluded from the study. Severity of AGA was evaluated with Norwood-Hamilton scale in men and Ludwig classification in women. ${ }^{13,15}$ Men with preservation of the frontal hairline were recorded as presenting 'female pattern'. Patients were divided into two subgroups: with and without AGA. Patients without AGA were defined as control group.

\section{Male-pattern baldness (Norwood-Hamilton scale)}

Type I: Minimal hair loss.

Type II: Minor recession of the frontotemporal hairline.

Type IIIa: The area of recession of the frontotemporal region is almost vertical with the front portion of the ear.

Type IIIv: In this type, hair loss is primarily in the vertex with possibly some frontal recession.

Type IV: Severe hair loss, especially in the frontal and frontotemporal hair, and significant diffuse hair thinning over the vertex. There is a broad band that separates vertex and the top of hair.

Type V: Hair loss at the vertex region is still separated from the frontotemporal region but the division is much less distinct.

Type VI: The bridge of hair that once crossed the crown is now been lost with only sparse hair remaining.

Type VII: Only a narrow band of hair in a horse- shoe shape survives on the sides and back of the scalp. Female-pattern AGA (Ludwig classification)

Grade I: Perceptible thinning of the hair on the crown with preservation of the frontal hairline

Grade II: Pronounced thinning of the hair on the crown

Grade III: Total baldness of the hair on the crown

\section{Statistical methods}

The analyses were performed by the Statistical Package for Social Sciences (SPSS) program, version 17.0. Descriptive statistics of the data, mean, standard deviation, rate and frequency values were used. The Chi-square test was used for the analysis of qualitative data. For the quantitative analysis of the data between independent samples, t-test was used. The Pearson correlation analysis was used to calculate severity analysis and correlation between different variables in the group. $P$ values less than 0,05 were considered statistically significant.

\section{RESULTS}

General frequency and age distribution

954 patients (535 women, 419 men) with a mean age of $37.70 \pm 15.41$, were enrolled in the study. AGA prevalence found was $67.1 \%(n=281)$ in men and $23.9 \%(n=128)$ in women. Control group was comprised of patients without AGA. Mean ages were $43.74 \pm 16.07,30.09 \pm 12,20,47.13 \pm 15.35,33.14 \pm 12.73$ in men with AGA, men without AGA, women with AGA and women without AGA, respectively. AGA was the reason for referral in only 3.9\% of women and $3.1 \%$ of men. Prevalence and severity of AGA were positively correlated with age in both genders $(p=0,0001)$. Prevalence of AGA in men older than 70 was $94 \%$, whereas it was $43.2 \%$ in those aged between $17-29,71.1 \%$ in men aged $30-39,77.2 \%$ in men aged $40-49$, $83.3 \%$ in men aged $50-59$, and $92.9 \%$ in men aged $60-69$. Prevalence of AGA in women older than 70 was $50 \%, 8.7 \%$ in women aged $17-$ $29,20.3 \%$ in women aged $30-39,29.2 \%$ in women aged $40-49,43 \%$ in women aged 50-59, and 68.3\% in women aged 60-69.

\section{Distribution of grade/severity of AGA according to age}

Mean age of AGA onset was $31.18 \pm 11.74$ in men and $40.35 \pm 15.25$ in women.

\section{a-Men}

The most common type was type $3 \mathrm{v}(24.1 \%)$ whereas the least common type was $3 a(0.5 \%)$. Prevalence of female pattern AGA in men was $2.9 \%(n=12)$. Type 2 was the most common type in men aged between 17-29 whereas type 7 was not detected in this age group. Type $3 \mathrm{v}$ was the most common type in men aged 30-69 and frequency of type 7 increased with age in this group. Type 7 was the most common type in men over 70 years. Female pattern AGA was most commonly seen in men older than 70 years (Table 1 ).

\section{b-Women}

The most common type was grade $1(17.2 \%)$ and the least common type was grade $3(0.2 \%)$ in women. Prevalence of AGA in women older than 70 was found in $50 \%, 8.7 \%$ among women aged $17-29,20.4 \%$ in women aged $30-39,29.2 \%$ in women aged $40-49$, 
$43.1 \%$ in women aged $50-59$, and $68.3 \%$ in women aged $60-69$. The most common type in women older than 70 years was grade 2 , in the rest of the women grade 1 was the most common type. Grade 3 was seen only in women older than 70 years (Table 2 ).

\section{Family history of AGA}

Of the 535 women in the study, $71.02 \%(n=380)$ had family history of AGA. The frequency of AGA was $25.5 \%(n=97)$ in this group. In the 155 patients without family history, the frequency of AGA found was $20 \%(n=35)$. The frequency of AGA was not statistically different between women with and without family history of AGA ( $\mathrm{p}=0.174)$.

Of the 419 men in the study, $78.28 \%(n=328)$ had family history of AGA. The frequency of AGA was $74.7 \%(n=245)$ in this group. In the 91 patients without family history, the frequency of AGA found was $39.6 \%(n=36)$. The frequency of AGA in men with family history of AGA was significantly higher than in men without family history of AGA ( $p=0,0001)$.

AGA frequency in fathers, brothers and second-degree relatives of men with AGA were significantly higher than in fathers, brothers and second-degree relatives of men without AGA $(\mathrm{p}=0.0001)$, but the frequency of maternal AGA was not statistically significant different between men with and without AGA ( $p>0.05)$.

AGA frequency in mothers and sisters were significantly higher in women with AGA compared with women without AGA ( $p=0.0001$ and $p=0.02$, respectively) but the frequency of AGA in fathers and second-degree relatives was not statistically significant different between women with and without AGA ( $p>0.05)$.

In men with paternal AGA history, AGA onset was significantly earlier than in men without paternal AGA history (mean \pm SD $29.87 \pm 11.36$ and $34 \pm 12.09$, respectively; $p=0.006$ ) whereas no significantly difference about age of AGA onset in women with and without maternal AGA history was found ( $p>0.05)$.

\section{Concomitant hyperandrogenemia symptoms}

Frequency of acne vulgaris in men without AGA was significantly higher than in men with AGA $(p=0.0001)$ but no statistically difference was found in terms of seborrhea $(p=0.270)$.

Frequency of acne vulgaris and seborrhea in women without AGA were significantly higher than in women with AGA $(p=0.0001)$ but there was no statistically significant difference in terms of hirsutism between women with and without AGA $(p=0.128)$.

SAHA syndrome was detected in 8 women (1.5\%). Frequency of SAHA syndrome in women with AGA was $6.25 \%$.

BMI, Concomitant systemic diseases, alcohol consumption and smoking habits

In the AGA group, $20 \%$ of women and $12 \%$ of men were obese, and $38 \%$ of women and $46 \%$ of men were overweight. There was no statistically significant difference in mean BMI values between patients with and without AGA in both genders $(p=0.157$ in women, $p=0.298$ in men). When men and women were divided into

Table 1: Prevalence of AGA in men according to age groups

\begin{tabular}{|c|c|c|c|c|c|c|}
\hline $\begin{array}{l}\text { Age } \\
\text { Grade }\end{array}$ & $\begin{array}{l}17-29 \\
n(\%) \\
(n=146)\end{array}$ & $\begin{array}{l}30-39 \\
n(\%) \\
(n=97)\end{array}$ & $\begin{array}{l}40-49 \\
n(\%) \\
(n=57)\end{array}$ & $\begin{array}{l}50-59 \\
n(\%) \\
(n=60)\end{array}$ & $\begin{array}{l}60-69 \\
n(\%) \\
(n=42)\end{array}$ & $\begin{array}{l}\geq 70 \\
\mathrm{n}(\%) \\
(\mathrm{n}=17)\end{array}$ \\
\hline Non-AGA & $83(56.8 \%)$ & $28(28.9 \%)$ & $13(22.8 \%)$ & $10(16.7 \%)$ & $3(7.1 \%)$ & $1(5.8 \%)$ \\
\hline Type 1 & $7(4.8 \%)$ & $4(4.1 \%)$ & $3(5.3 \%)$ & $1(1.7 \%)$ & 0 & 0 \\
\hline Type 2 & $18(12.3 \%)$ & $7(7.2 \%)$ & $3(5.3 \%)$ & $3(5 \%)$ & $1(2.4 \%)$ & $1(5.9 \%)$ \\
\hline Type $2 \mathrm{a}$ & $2(1,4 \%)$ & $1(1 \%)$ & 0 & 0 & 0 & 0 \\
\hline Type 3 & $9(6.2 \%)$ & $5(5.2 \%)$ & $1(1.8 \%)$ & $2(3.3 \%)$ & 0 & $1(5.9 \%)$ \\
\hline Type $3 a$ & $1(0.7 \%)$ & 0 & 0 & 0 & 0 & $1(5.9 \%)$ \\
\hline Type 3v & $18(12.3 \%)$ & $28(28.9 \%)$ & $18(31.6 \%)$ & $18(30 \%)$ & $17(40.5 \%)$ & $2(11.8 \%)$ \\
\hline Type 4 & $1(0.7 \%)$ & 0 & $2(3.5 \%)$ & $2(3.3 \%)$ & $2(4.8 \%)$ & 0 \\
\hline Type $4 a$ & 0 & $2(2.1 \%)$ & 0 & 0 & $1(2.4 \%)$ & 0 \\
\hline Type 5 & $1(0.7 \%)$ & $1(1 \%)$ & 0 & $1(1.7 \%)$ & $1(2.4 \%)$ & 0 \\
\hline Type $5 a$ & 0 & $3(3.1 \%)$ & $5(8.8 \%)$ & $2(3.3 \%)$ & 0 & 0 \\
\hline Type 6 & 0 & $9(9.3 \%)$ & $4(7 \%)$ & $4(6.7 \%)$ & $2(4.8 \%)$ & $2(11.8 \%)$ \\
\hline Type 7 & 0 & $8(8.2 \%)$ & $6(10.5 \%)$ & $15(25 \%)$ & $15(35.7 \%)$ & $8(47.1 \%)$ \\
\hline Female pattern & $6(4.1 \%)$ & $1(1 \%)$ & $2(3.5 \%)$ & $2(3.3 \%)$ & 0 & $1(54.9 \%)$ \\
\hline
\end{tabular}

TABle 2: Prevalence of AGA in women according to age

\begin{tabular}{|c|c|c|c|c|c|c|}
\hline $\begin{array}{l}\text { Age } \\
\text { Grade }\end{array}$ & $\begin{array}{l}17-29 \\
n(\%) \\
(n=219)\end{array}$ & $\begin{array}{l}30-39 \\
n(\%) \\
(n=113)\end{array}$ & $\begin{array}{l}40-49 \\
n(\%) \\
(n=89)\end{array}$ & $\begin{array}{l}50-59 \\
n(\%) \\
(n=65)\end{array}$ & $\begin{array}{l}60-69 \\
n(\%) \\
(n=41)\end{array}$ & $\begin{array}{l}\geq 70 \\
n(\%) \\
(n=8)\end{array}$ \\
\hline Non-AGA & $200(91.3 \%)$ & $90(79.6 \%)$ & $63(70.8 \%)$ & 37 (56.9\%) & $13(31.7 \%)$ & $4(50 \%)$ \\
\hline Grade 1 & $18(8.2 \%)$ & $17(15 \%)$ & $20(22.5 \%)$ & $19(29.2 \%)$ & $17(41.5 \%)$ & $1(12.5 \%)$ \\
\hline Grade 2 & $1(0.5 \%)$ & $6(5.3 \%)$ & $6(6.7 \%)$ & $9(13.8 \%)$ & $11(26.8 \%)$ & $2(25 \%)$ \\
\hline Grade 3 & 0 & 0 & 0 & 0 & 0 & $1(12.5 \%)$ \\
\hline
\end{tabular}


three categories as normal, overweight and obese according to BMI, there were no significant difference in terms of frequency and severity of AGA between the groups ( $p>0.05$ ).

The frequency of accompanying systemic diseases did not differ between patients and controls when compared according to age $(p>0.05)$. Nonetheless, in men with AGA between the age of 50 59 , frequency of hypertension was significantly higher than the men in same age group without AGA $(\mathrm{p}<0.05)$.

However, no significant difference was found in terms of alcohol consumption and smoking habits between patients with and without AGA in both genders ( $p>0.05)$.

\section{Menstrual cycle in women}

Of the 535 women in the study; $22.4 \%(n=120)$ was postmenopausal, and $77.6 \%(n=415)$ was premenopausal. Frequency of AGA was $49.16 \%$ in postmenopausal women and $16.62 \%$ in premenopausal women. Prevalence of AGA was significantly higher in postmenopausal women $(\mathrm{p}=0.0001)$. Menstrual irregularity was found in $18.9 \%(n=101)$ of women. Frequency of AGA was $20.58 \%$ in this group.

PCOS was found in $2.2 \%(n=12)$ of women in the study. Their mean age was $27.08 \pm 4.12$. Frequency of AGA was $16.6 \%(n=2)$ in women with PCOS, both were grade 1.

\section{DISCUSSION}

In the literature, different results have been reported particularly in men based on ethnic groups about prevalence of AGA. Firstly according to Hamilton's study in 1951, by the age of 30 years the mean prevalence was $30 \%, 40 \%$ in mid-forties, and this rate rises to $50 \%$ by the age of 50 years in Caucasian men. ${ }^{12}$ In our study, these rates were respectively $71.1 \%, 77.2 \%$ and $83.3 \%$. In studies from US, Italy, Norway and Australia similar results to Hamilton's study were reported. ${ }^{10,23,24,25}$

In another study, Birch et al. reported that the prevalence of female type AGA in women younger than 50 years was $6 \%$, whereas in women older than 50 years, the prevalence of female AGA was $52.6 \%$ in England. ${ }^{21}$

Paik et al. found that prevalence of AGA in Korea was 14.1\% in men, $5.6 \%$ in women. ${ }^{1}$ This result is similar to other reported studies in Africa but lower than in our study and other reported studies in Caucasians.

In our study, AGA was the reason for referral in only $3.9 \%$ in women and $3.1 \%$ in men; however AGA was found in $67.1 \%$ of men and $23.9 \%$ in women. This result may be attributed to low level of knowledge on AGA and treatment options.

Paik et al. indicated that prevalence of AGA increased with age in both genders as in our study and the most common type was type 6 over the age of 70 years and type $3 \mathrm{v}$ between the age of $30-70$ in Korea. ${ }^{1}$ In our study we found that the most common type was type 7 over the age of 70 years, similar to Korean population; type $3 \mathrm{v}$ between the age of 30-70. Female pattern AGA was seen in 12 men (2.9\%) in our study and in 13 men $(1.8 \%)$ in another study from Taiwan. ${ }^{26}$ However, many studies have reported a considerable amount of female pattern AGA in men. ${ }^{1,5,10,26}$ This results suggest that female pattern AGA should be included in classification of male pattern AGA.
In our study, grade 1 was the most common type in women younger than 70 years, according to Ludwig classification, and grade 2 was the most frequent in those older than 70 years. Paik et al. reported that Ludwig grade 1 was the most common type in women younger than 60 years and grade 1 and 2 older than 60 years and they did not detect grade 3 in any patient. ${ }^{1}$

In this study we found that not only the prevalence of AGA but also the severity of AGA increase with age. Conversely, Su et al. reported no correlation between the severity of AGA and age. ${ }^{26}$ This result may be attributed to inclusion of patients with at least grade 3 AGA whereas we included all patients with AGA, including grade 1.

Some studies have reported that prevalence of AGA in men increases with positive paternal AGA history. ${ }^{26,27}$ Similarly in our study, prevalence of AGA in men increased with AGA history of father, brother and second-degree relatives but there was no correlation with maternal AGA history. However, we detected that prevalence of AGA in women increased with positive AGA history in mother and sister but there was no correlation with AGA history of father and second-degree relatives. Many studies have reported different results about relation between family history and prevalence of AGA. 1,5,7,26,27 The reason of this difference is unknown but it may be due to genetic variation. In this study, age of AGA onset was significantly lower in men with positive paternal AGA history. Similarly Su et al. reported a correlation between the early age of AGA onset and positive family history. ${ }^{26}$

In this study, the frequency of seborrhea and acne in women with AGA were significantly higher than in women without AGA. Conversely, another study reported no difference in terms of sebum production between women with and without AGA..$^{28}$ However, in our study, there was no difference in seborrhea between men with and without AGA but frequency of acne in men without AGA was significantly higher than in men with AGA. But another study conducted by Severy et al. reported no significant difference between presence of acne and AGA. ${ }^{10}$ High frequency of acne in men without AGA may be explained with relatively younger age of this group. We detected hirsutism in 24 women (18.7\%) but there was no significant difference between women with and without AGA.

History of menstrual disorder was seen in $16.4 \%$ of women but no significant difference was found between women with and without AGA. We found that the frequency of AGA in postmenopausal women was higher than in premenopausal women. This result may be explained by the mean age of women with AGA, which was higher than in women without AGA.

In our study, in the AGA group, $20 \%$ of women and $12 \%$ of men were obese, $38 \%$ of women and $46 \%$ of men were overweight. However, we didn't find any correlation between BMI and prevalence or severity of AGA in both genders similar to some other studies. ${ }^{26,28,29,30}$

An association between AGA and BMI was reported in only one of the four previous case-control studies..$^{14,17,31,32}$ In another study conducted in 116 men with AGA and 100 healthy controls, BMI in patients was higher than in control group and the authors attributed this result to deterioration of balance of elements as zinc and copper in hair with obesity. ${ }^{33}$ 
Some studies reported that frequency of HT increased in patients with AGA..$^{30,34,35}$ Conversely, in other studies there were no significant differences in terms of risk factors of CVD between men with and without AGA. ${ }^{31,35}$

Studies on the association between metabolic syndrome, DM and AGA have reported conflicting results..$^{17,18,36-38}$ In our study the frequency of accompanying systemic diseases did not differ between patients and controls in comparison according to age $(p>0.05)$. Nonetheless, in men with AGA aged 50-59, frequency of hypertension was significantly higher than the men in same age group without AGA $(\mathrm{p}<0.05)$. But this result should be interpreted carefully because of very small number of patients $(n=10)$ in this age group. Controversial results were reported between alcohol consumption/smoking and AGA. ${ }^{10,26}$ We did not find any significant difference in the terms of alcohol consumption and smoking between patients and control group $(\mathrm{p}>0.05)$.

\section{Limitations}

Although other causes of alopecia were excluded, differentiation of Ludwig grade 1 from telogen effluvium without further tests and biopsy is difficult.

\section{CONCLUSIONS}

In our study prevalence of AGA were higher than the previous studies in Asian countries and Caucasian race. This result may be due to hospital-based design of our study. Paternal AGA seems to be an important risk factor for early onset of AGA in men. Early diagnosis and preventive treatment should be aimed in men with paternal AGA history. Despite the high prevalence of AGA in our study, low rate of referral for AGA may be related to low level of knowledge on AGA and treatment options. We believe patients should be informed about AGA. In our study no significant association was found between AGA prevalence or severity and systemic diseases or BMI. Further studies with larger populations are needed to elucidate the relation between AGA and systemic diseases. 


\section{REFERENCES}

1. Paik JH, Yoon JB, Sim WY, Kim BS, Kim NI. The prevalence and types of androgenetic alopecia in Korean men and women. Br J Dermatol. 2001;145:95-9.

2. Yang CC, Hsieh FN, Lin LY, Hsu CK, Sheu HM, Chen W. Higher body mass index is associated with greater severity of alopecia in men with male-pattern androgenetic alopecia in Taiwan:A cross-sectional study. J Am Acad Dermatol. 2014;70:297302.e1.

3. Ellis JA, Sinclair R, Harrap SB. Androgenetic alopecia: pathogenesis and potential for therapy. Expert Rev Mol Med. 2002;4:1-11.

4. Di Loreto C, La Marra F, Mazzon G, Belgrano E, Trombetta C, Cauci S. Immunohistochemical evaluation of androgen receptor and nerve structure density in human prepuce from patients with persistent sexual side effects after finasteride use for androgenetic alopecia. PLoS One. 2014;9:e100237.

5. Wang TL, Zhou C, Shen YW, Wang XY, Ding XL, Tian S, et al. Prevalence of androgenetic alopecia in China: a community-based study in six cities. $\mathrm{Br} \mathrm{J}$ Dermatol. 2010;162:843-7.

6. Borlu M, Ukşal Ü, Utaş S, Bayram F, Muderris I. Androgenetik alopesili 59 kadın hastada hiperandrojenizm ve polikistik over sendromu. Türkderm. 2004;38:10610.

7. $\quad$ Xu F, Sheng YY, Mu ZL, Lou W, Zhou J, Ren YT, et al. Prevalence and types of androgenetic alopecia in Shanghai, China: a community-based study. $\mathrm{Br} \mathrm{J}$ Dermatol. 2009 Mar;160(3):629-32.

8. Cash TF. The psychosocial consequences of androgenetic alopecia: a review of the research literature. Br J Dermatol. 1999;141:398-405.

9. Schmidt S, Fischer TW, Chren MM, Strauss BM, Elsner P. Strategies of coping and quality of life in women with alopecia. Br J Dermatol. 2001;144:1038-43.

10. Severi G, Sinclair R, Hopper JL, English DR, McCredie MR, Boyle P, et al. Epidemiology and health services research. Androgenetic alopecia in men aged 40-69 years: prevalence and risk factors. Br J Dermatol. 2003;149:1207-13.

11. Krupa Shankar D, Chakravarthi M, Shilpakar R. Male androgenetic alopecia: Population-based study in 1,005 subjects. Int J Trichology. 2009;1:131-3.

12. Hamilton JB. Patterned long hair in man; types and incidence. Ann N Y Acad Sci. $1951 ; 53: 708-28$

13. Norwood OT. Incidence of female androgenetic alopecia (female pattern alopecia). Dermatol Surg. 2001;27:53-4.

14. Acibucu F, Kayatas M, Candan F. The association of insulin resistance and metabolic syndrome in early androgenetic alopecia. Singapore Med J. 2010;51:931-6.

15. Ludwig E. Classification of the types of androgenetic alopecia (common baldness) occuring in the female sex. Br J Dermatol. 1977;97:247-54.

16. Levy LL, Emer JJ. Female pattern alopecia: current perspectives. Int J Womens Health. 2013;5:541-56.

17. Arias-Santiago S, Gutiérrez-Salmerón MT, Castellote-Caballero L, Buendía-Eisman A, Naranjo-Sintes R. Androgenetic alopecia and cardiovasculer risk factors in men and women: a comparative study. J Am Acad Dermatol. 2010;63:420-9.

18. Su LH, Chen LS, Lin SC, Chen HH. Association of androgenetic alopecia with mortality from diabetes mellitus and heart disease. JAMA Dermatol. 2013;149:601-6.

19. Cornier MA, Dabelea D, Hernandez TL, Lindstrom RC, Steig AJ, Stob NR, et al. The metabolic syndrome. Endocr Rev. 2008;29:777-822.

20. Haslam DW, James WP.. Obesity. Lancet. 2005;366:1197-209.

21. Birch MP, Messenger JF, Messenger AG. Hair density, hair diameter and the prevalence of female pattern hair loss. Br J Dermatol. 2001;144:297-304.

22. Booth ML, Hunter C, Gore CJ, Bauman A, Owen N. The relationship between body mass index and wa-ist circumference: implications for estimates of the population prevalence of overweight. Int J Obes Relat Metab Disord. 2000;24:1058-61.

23. Rhodes T, Girman CJ, Savin RC, Kaufman KD, Guo S, Lilly FR, et al. Prevalence of male pattern hair loss in 18-49 year old men. Dermatol Surg. 1998;24:1330-2.

24. DeMuro-Mercon C, Rhodes T, Girman CJ, Vatten L. Male-pattern hair loss in Norwegian men: a community-based study. Dermatology. 2000;200:219-22.

25. Gan DC, Sinclair RD. Prevalence of male and female pattern hair loss in Maryborough. J Investig Dermatol Symp Proc. 2005;10:184-9.

26. Su LH, Chen TH. Association of androgenetic alopecia with smoking and its prevalence among Asian men: a community-based study. Arch Dermatol. 2007;143:1401-6.

27. Chumlea WC, Rhodes T, Girman CJ, Johnson-Levonas A, Lilly FR, Wu R, Guo SS, et al. Family history and risk of hair loss. Dermatology. 2004;209:33-9.
28. Birch MP, Lashen H, Agarwal S, Messenger AG. Female pattern hair loss, sebum excretion and the end-organ response to androgens. Br J Dermatol. 2006;154:85-9.

29. Sharma L, Dubey A, Gupta PR, Agrawal A. Androgenetic alopecia and risk of coronary artery disease. Indian Dermatol Online J. 2013;4:283-7.

30. Ellis JA, Stebbing M, Harrap SB. Male pattern baldness is not associated with established cardiovascular risk factors in the general population. Clin Sci (Lond). 2001;100:401-4.

31. Matilainen V, Koskela P, Keinänen-Kiukaanniemi S. Early androgenetic alopecia as a marker of insulin resistance. Lancet. 2000;356:1165-6.

32. González-González JG, Mancillas-Adame LG, Fernández-Reyes M, Gómez-Flores M, Lavalle-González FJ, Ocampo-Candiani J, et al. Androgenetic alopecia and insulin resistance in young men. Clin Endocrinol (Oxf). 2009;71:494-9.

33. Ozturk P, Kurutas E, Ataseven A, Dokur N, Gumusalan Y, Gorur A, et al. BMl and levels of zinc, copper in hair, serum and urine of Turkish male patients with androgenetic alopecia. J Trace Elem Med Biol. 2014;28:266-70.

34. Ahouansou S, Le Toumelin P, Crickx B, Descamps V. Association of androgenetic alopecia and hypertension. Eur J Dermatol. 2007;17:220-2.

35. Aslan Sezgin S, Altunay, Köşlü A. Androgenetik alopeside koroner arter hastalığı risk faktörleri. Türkderm. 2000;34:95-9.

36. Mansouri P, Mortazavi M, Eslami M, Mazinani M. Androgenetic alopecia and coronary artery disease in women. Dermatol Online J. 2005;11:2.

37. Yi SM, Son SW, Lee KG, Kim SH, Lee SK, Cho ER, et al. Gender-spesific association of androgenetic alopecia with metabolic syndrome in a middle-aged Korean population. Br J Dermatol. 2012;167:306-13.

38. Su LH, Chen TH. Association of androgenetic alopecia with metabolic syndrome in men: a community-based survey. Br J Dermatol. 2010;163:371-7.
MAILING ADDRESS:
Kubra Esen Salman
Sisli Hamidiye Etfal Egitim ve Arastirma Hastanesi
Dermatoloji Klinigi
34371 Şişli/Istanbul, Turquia
Email: esenkbra@gmail.com

How to cite this article: Esen Salman K, Kivanc Altunay I, Kucukunal NA, Aksu Cerman A. Frequency, severity and related factors of androgenetic alopecia in dermatology outpatient clinic: hospital-based cross-sectional study in Turkey. An Bras Dermatol. 2017;92(1):35-40. 